\title{
ARQUEOLOGIA COMO PRÁTICA POLÍTICA
}

Lúcio Menezes Ferreira Universidade Federal de Pelotas

Pedro Paulo Abreu Funari Universidade Estadual de Campinas

Aarqueologia iniciou-se, como disciplina científica, na esteira do imperialismo das grandes potências. A empreitada arqueológica inseria-se no domínio colonial, como parte de disputas estratégicas. Não à toa, os arqueólogos ligavam-se aos serviços militares ou de informação e serviam a agendas voltadas para o controle material e ideológico das periferias. Ao lado dessa vertente imperial, a disciplina, ab initio, esteve imbricada na construção de identidades nacionais, de cunho masculino, tendo como objetivo a coesão social e a uniformidade, no presente e no passado. A disciplina, assim, surgia e firmava-se como parte do amplo espectro de agenciamentos das normatizações, tanto em âmbito interno, em cada Estado Nacional, como na relação com os sujeitos externos da opressão, nas periferias asiática, africana, médio-oriental e latinoamericana.

Esse quadro mudou radicalmente nas últimas décadas. Nas potências centrais, emergiram grupos sociais e de interesse que implodiram as pretensões de homogeneidade e subordinação às normas, tão bem articuladas no primeiro século e meio da incipiente arqueologia. Nas sociedades ocidentais, as mulheres, antes ausentes ou subjugadas, emergiram como sujeitos sociais cada vez mais ativos. Se até a Segunda Guerra Mundial (1939-1945) as arqueólogas eram raras e em posições subalternas, depois disso multiplicaram-se e assumiram, muitas vezes, um protagonismo notável. Quem não há de lembrar-se de Kathleen Kenyon (1952), notável pioneira que inspirou tantas jovens arqueólogas a partir da década de 1940. Rompida esta barreira, outras muitas foram superadas, com o reconhecimento da diversidade de grupos humanos: hoje não causa espanto a arqueologia de gênero, queer ou a variedade de sexualidades, tanto dos arqueólogos, como dos seus temas de investigação (Schmidt e Voss, 2000).

No âmbito internacional, essas modificações não foram menos importantes. A arqueologia tornou-se prática também periférica. Não apenas das elites das antigas colônias, mas espraiando-se ainda para os povos indígenas, as minorias, os subalternos. Um passo decisivo para essa nova configuração foi dado pela constituição do Congresso Mundial de Arqueologia, em 1986, com seu combate às hierarquias entre ricos e pobres, acadêmicos e público ou outras quaisquer (Funari, 2006). A arqueologia, de estudo do antigo, passou, como propugnavam em 1987 Michael Shanks e Christopher Tilley (1987), a ser o estudo das relações de poder. Michel Foucault (1969) e sua "Arqueologia do Saber" tornaram-se parte da reflexão da disciplina, e seu caráter político e social passou a ocupar cada vez mais o lugar de destaque.

Nestas circunstâncias, entende-se este número especial do Boletim do Museu Paraense Emílio Goeldi. Ciências

Humanas, dedicado à "Arqueologia Amazônica". Em artigo de abertura, que serve como introdução teórica ao número, Cristóbal Gnecco desmonta as engrenagens da arqueologia como máquina de violência epistemológica. Enfatiza como a disciplina aparelha-se como instrumento de violência ao forjar, na bigorna de projetos nacionais e coloniais, identidades culturais essencializadas. Longe de desmontar essa maquinaria, a arqueologia latinoamericana contemporânea, agora parafusada pelas políticas do multiculturalismo, reproduz a diferença cultural como entidade essencializada e constroi novos nacionalismos étnicos. Não superou, portanto, os projetos nacionalistas e colonialistas de aglutinação e normalização das diferenças culturais e, tampouco, renunciou à apropriação do conhecimento histórico dos grupos 
subalternos. A descolonização das metodologias e narrativas arqueológicas' inventa-se, na verve latinoamericana de Gnecco, como arqueologia relacional, aberta ao diálogo com o público e com os movimentos sociais.

Para Gnecco, a interação com as comunidades e um olhar crítico são, portanto, fundamentais, promovendo, inclusive, avanços na pesquisa arqueológica. $O$ artigo de Fabíola Andréa Silva, de cunho etnoarqueológico, exemplifica essa proposição de Gnecco. A autora, que há mais de uma década faz pesquisas de campo em terras indígenas do Mato Grosso e Mato Grosso do Sul (Silva et al., 2007), demonstra que os grupos indígenas têm suas próprias representações sobre os vestígios arqueológicos e acerca dos significados da pesquisa arqueológica. Pode-se dizer, inclusive, que Fabíola Andréa Silva desenvolve pesquisas em arqueologia comunitária, pois considera as representações das comunidades como elementos indiscerníveis das interpretações arqueológicas². Assim é que, como argumenta a autora, a arqueologia e etnoarqueologia podem reforçar a luta indígena pela soberania territorial, pela preservação da biodiversidade e da sociodiversidade.

A autora ressalta, ainda, a importância da etnoarqueologia para o conhecimento dos processos de produção, usos, distribuição e variabilidade dos artefatos no tempo e no espaço. $\bigcirc$ artigo de Martijn van den Bel mostra a justeza desse raciocínio. O autor indica como o estudo etnoarqueológico da atual produção cerâmica dos Palikur, que vivem na Guiana Francesa e no Amapá, permite o entendimento mais acurado dos complexos cerâmicos pré-colombianos.

Realizando rigoroso trabalho de campo entre 1994 e 1998, van den Bel aquilatou informações preciosas para as pesquisas arqueológicas na Amazônia: os usos rituais das cerâmicas em eventos públicos como casamentos, iniciação e morte; o sistema pictográfico impresso nos motivos decorativos das cerâmicas e suas profundas articulações com a história oral, as estruturas sociais e a identidade cultural dos Palikur. Martijn van den Bel atenta, ainda, para os processos de continuidade e de mudança culturais refletidos nas cerâmicas. Aponta que o colonialismo europeu, ainda imperante na região, abalou catastroficamente a densidade demográfica e o habitus dos Palikur e demais grupos indígenas amazônicos, levando-os a reelaborar suas identidades nas estampas da cultura material e nas fábulas da história oral.

O artigo de Juliana Salles Machado também se envereda pelos processos históricos de continuidade e de mudança cultural na arqueologia amazônica. A autora examina, inicialmente, os conceitos de continuidade utilizados pelos arqueólogos, desvelando suas implicações epistemológicas. Apresenta, depois, os resultados de suas pesquisas etnoarqueológicas realizadas na ilha Caviana (PA), sublinhando que as geneticamente híbridas populações ribeirinhas da região mantêm laços de continuidade com os grupos indígenas do passado. Estribando-se numa gama variada de antropólogos e arqueólogos que trabalham na Amazônia, a autora argumenta que as populações ribeirinhas não apenas se assentam em sítios arqueológicos, como também reproduzem, reelaborando-os, modelos de interação com o ambiente e padrões tecnológicos indígenas.

Três traços, para além da etnoarqueologia, enfeixam esses artigos: a exemplo do artigo de Gnecco, concebem a arqueologia como prática política; percorrem, cada um a seu modo, as trilhas da história das pesquisas arqueológicas na Amazônia; refletem sobre as relações entre arqueologia e fabricação de identidades culturais. $\bigcirc$ artigo de Lúcio Menezes Ferreira também segue essa pauta. Analisa as contribuições do zoólogo Emílio Augusto Goeldi para a arqueologia amazônica. Pontua como Goeldi estava plenamente inteirado do debate arqueológico nacional e internacional, organizou as coleções arqueológicas e etnográficas do Museu Paraense de História Natural e Etnografia e circunscreveu um problema regional de pesquisa.

O conceito de descolonização das metodologias arqueológicas surgiu no contexto australiano, com desdobramentos pela Europa e América Latina. A esse respeito, ver Smith (1999) e Smith e Wobst (2005).

2 Sobre arqueologia comunitária, ver os seguintes artigos de síntese: Marshall (2002) e Tully (2007). 
Calcando-se em literatura pós-colonial e em análises recentes em história da arqueologia, explora as relações entre as pesquisas arqueológicas de Goeldi e uma política colonial. Ao explorá-las, o autor não faz de Goeldi uma espécie de Kreigton, o espião, administrador colonial e antropólogo do romance "Kim", de Rudyard Kipling (1954). Por outra, não transforma Goeldi num agente do império. Destaca notadamente uma dimensão específica das políticas coloniais: exatamente aquela que faz da arqueologia instrumento de apropriação simbólica de territórios. A intenção, pois, não é minorar as contribuições de Goeldi à arqueologia amazônica. Mas, sim, situá-las no contexto mais geral, político e científico, de onde elas brotam.

Até mesmo porque as contribuições de Goeldi para a arqueologia amazônica são, indubitavelmente, valiosas. É o que evidenciam Nelson Sanjad e João Batista Poça da Silva, no texto de abertura da seção "Memória" desse número. Os autores nos brindam com a tradução, para o vernáculo, de três textos arqueológicos e etnológicos de Goeldi, escritos, em alemão, entre 1900 e 1906. Os autores cumprem, assim, um papel inestimável, ao traduzir textos de Goeldi cujo acesso é difícil ao público. As traduções são precedidas por comentários que contextualizam os textos de Goeldi, vinculando-os acertadamente à escola etnológica alemã e aos interesses do zoólogo pela lingüística e pelo estudo da cultura material.

A seção "Memória" traz mais três importantes trabalhos. Klaus Hilbert apresenta a versátil vida de Peter Paul Hilbert. Trata-se de um texto biográfico. De um filho escrevendo sobre o pai. Em sua prosa clara e límpida, Klaus Hilbert não disfarça ternura e admiração pelo pai. Não escamoteia sua perspectiva pessoal sob o manto protetor da objetividade científica e, tampouco, a disfarça numa pretensa distância narrativa. Klaus Hilbert equilibra, assim, emoção e análise, contando-nos a história de um pesquisador pouco conhecido pelo público, que entre 1948 e 1961 foi arqueólogo do Museu Paraense Emílio Goeldi e, entre outros trabalhos, acompanhou o casal Betty J. Meggers e Clifford Evans em suas primeiras pesquisas na Amazônia, realizadas a partir de 1949.

Anna Roosevelt, no terceiro texto da seção "Memória”, escreve uma história de suas pesquisas na Amazônia. Apesar de ser uma das mais importantes arqueólogas que pesquisaram na região, e talvez por isso mesmo, Roosevelt descreve seu trabalho sem jactância. Seu tom é sóbrio e moderado. Conta-nos quais foram as influências teóricas, os eventos e as colaborações com instituições e acadêmicos que a motivaram a interessar-se pela arqueologia amazônica. Examina suas pesquisas na Venezuela e seus primeiros trabalhos de campo na Amazônia. Discute, em seguida, os debates teóricos gerados por seus projetos de pesquisa no Baixo Amazonas. Por fim, por meio da comparação entre seus trabalhos no Brasil e na África Central, reflete sobre evolução humana, ecologia humana e história cultural.

O quarto texto da seção "Memória", de Edithe da Silva Pereira, esboça um perfil das pesquisas realizadas pela equipe de arqueólogos do Museu Paraense Emílio Goeldi nos últimos dezessete anos (1991-2008). A autora argumenta que esse período propeliu um salto qualitativo não apenas na história da pesquisa arqueológica do Museu, como também da arqueologia amazônica em sua totalidade. $\bigcirc$ protagonismo da instituição no palco da arqueologia amazônica, segundo a autora, revela-se no ineditismo de seus temas de pesquisa, no aprimoramento de seus quadros profissionais, na qualidade de sua infra-estrutura, na abrangência de seus acervos e, finalmente, na relevância de seus trabalhos em educação patrimonial.

Este número especial do Boletim do Museu Paraense Emílio Goeldi. Ciências Humanas, em suma, mostra parte da pluralidade dos personagens, histórias e identidades em jogo na arqueologia amazônica. Mostra, ainda, que a Amazônia, região periférica do mundo, encontra-se na encruzilhada das reflexões contemporâneas sobre arqueologia como prática política.

Boa leitura! 


\section{REFERÊNCIAS}

FOUCAULT, Michel. L’Archéologie du Savoir. Paris: Gallimard, 1969.

FUNARI, Pedro Paulo A. The World Archaeological Congress from a critical and personal perspective. Archaeologies, v. 2, n. 1, p. $73-79,2006$.

KENYON, Kathleen. Beginning in Archaeology. Londres: Aldine, 1952.

KIPLING, Rudyard. Kim. São Paulo: Companhia Editora Nacional, 1954[1901].

MARSHALL, Yvonne. What is Community Archaeology? World Archaeology, v. 32, n. 2, p. 211-219, 2002.

SCHMIDT, Robert A.; VOSS, Barbara (Eds.). Archaeologies of Sexuality. Londres: Routledge, 2000.

SHANKS, Michael; TILLEY, Christopher. Re-constructing archaeology. Cambridge: Cambridge University Press, 1987.

SILVA, Fabíola Andréa; BESPALEZ, Eduardo; STUCHI, Francisco Forte; POUGET, Frederic Caíres. Arqueologia, Etnoarqueologia e História Indígena - um estudo sobre a trajetória de ocupação indígena em territórios do Mato Grosso e Mato Grosso do Sul: a terra indígena Kayabi e a aldeia Lalima. Revista do Museu de Arqueologia e Etnologia, v. 17, p. 509-514, 2007.

SMITH, Linda Tuhiwai. Decolonizing Methodologies: Research and Indigenous People. Dunedin: University of Otago Press, 1999.

SMITH, Claire; WOBST, Martin H. (Eds.). Indigenous Archaeologies: Decolonizing Theory and Practice. London: Routledge, 2005.

TULLY, Gemma. Community Archaeology: General Methods and Standards of Practice. Public Archaeology, v. 6, p. 155-187, 2007. 